\title{
LOS DICCIONARIOS DIDÁCTICOS DEL ESPAÑOL DESDE LA PERSPECTIVA DE SUS DESTINATARIOS
}

\author{
DOLORES AZORÍN FERNÁNDEZ \\ (Universidad de Alicante)
}

\begin{abstract}
The position that dictionaries place in the teaching of Spanish as a mother language is far from the point they deserve, specially if we consider their great usefulness as a learning instrument. Through an inquest taken to a representative group of students and teachers of high school centres, we have confirmed our hypothesis that dictionaries have not received the attention they need, although they offer us a multiple choices to develop the teaching-learning process of a mother language.
\end{abstract}

\section{Los diccionarios didácticos: concepto y delimitación}

Uno de los principales parámetros de diferenciación de las obras lexicográficas cs el tipo de usuario al que se destinan, si bien, en las tipologías más comúnmente extendidas, este rasgo a menudo no se contempla o no se enfatiza lo suficiente'. De

\footnotetext{
${ }^{1}$ En la mayoría de las clasificaciones tipológicas no se utiliza la naturalcza del destinatario de la obra como criterio diferenciador. Esto se debe, a nuestro juicio, a que las clasificaciones parten de las características intcrnas (lingüísticas) de los diccionarios existentes para proceder a la agrupación postcrior de los mismos en diferentes categorías y tipos: monolingües/plurilingües, descriptivo/normalivo, sincrónico/diacrónico, general/especializado, etc. El destinatario se ha venido considerando cono un parámetro externo $y$, por lo tanto, no susceptible de convertirse en eje vertebrador para estableccr un «lipo de diccionario». Así, por ejemplo, G. Haensch (1981: 156 y sigs.), diferencia entre criterios linguísticos y prácticos a la hora de establecer su clasificación tipológica de las obras lexicográficas. Uno de los criterios prácticos consiste en «las finalidades específicas de los diccionarios» - que pueden ser tantas como se pueda imaginar, ya que no está restringido el concepto de «linalidad»-- una de estas finalidades tiene que ver con el tipo de destinatario: para el hablante nativo de la lengua de que se trate se destina el dicionario de uso, mientras que para el hablante que está aprendiento esa misma lengua cono extranjera, se destina el diccionario de aprendizajc.
} 
hecho, en la investigación metalexicográfica, hasta hace relativamente escasos años, no se ha planteado de manera rigurosa el problema de la relación entre el diccionario y sus destinatarios, cuando «serían notables los progresos -como afirma Hernández, (1998: 50)_ [...] si se reconociera definitivamente la necesidad de adoptar en la investigación lexicográfica una decidida orientación hacia el consultor del diccionario».

En el ámbito anglosajón, que cuenta con una dilatada tradición en la didáctica del inglés como lengua extranjera, la consideración de las necesidades de los usuarios, sobre todo de los que se enfrentan al aprendizaje de una segunda lengua, ha traído como resultado la eclosión de la llamada «lexicografía pedagógica», «didáctica» o de «aprendizaje» como campo para la indagación teórica y para las realizaciones prácticas. El espectacular despliegue que dentro de la industria editorial ha cxperimentado el sector del diccionario didáctico invita a reflexionar acerca de los fundamentos lingüísticos y pedagógicos que han propiciado el surgimiento de esta modalidad lexicográfica ${ }^{2}$.

De manera general, los destinatarios de la obra lexicográfica pueden dividirse en dos categorías básicas atendiendo a su nivel de conocimiento de la lengua de que se trate:

1. Los que han alcanzado un dominio pleno de la lengua de referencia.

2. Los que no han conseguido llegar al estadio anterior ${ }^{3}$ :

a) Bien por encontrarse en fase de aprendizaje de su propia lengua

b) Bien por estar adquiriendo una segunda

Fruto de su todavía deficiente conocimiento de las estructuras lingüísticas y de las normas que regulan su actualización en el discurso, los usuarios del tipo 2 comparten una serie de limitaciones que les impide, en diversa medida, producir y cntender enunciados con la misma fluidez con que son capaces de hacerlo los del tipo I. Es obvio que para estos usuarios — nativos o extranjeros- los diccionarios comunes, cn cualquiera de sus modalidades y formatos, no son el instrumento adecuado para atender a sus dudas, puesto que la mayoría de estas obras tienen como destinatario al hablante nativo adulto, de cultura media, cuyo nivel de competencia linguístico-comunicativa hace innecesario que el lexicógrafo se

\footnotetext{
2 Para el inglés, por ejemplo, M. Rundell (1998: 315) reconocía que «The English monolingual learner's dictionary (MLD) currently occupies one of the most fiercely competitive marktplaces in the publishing worlds.

"Dentro de este último grupo cabría diferenciar, por un lado, los usuarios que estudian una lengua extranjera y para quienes, en un principio, se recomendarían los diccionarios bilinguies; y por otro lado, los escolares que aprenden a perfeccionar su propia lengua materna, inserto este aprendizaje en la planificación curricular de los ciclos formativos básico y medio de la enseñanza. Para estos áltimos usuarios, el diccionario monolingüe de aprendizaje o escolar, adaptado a su nivel de estudios, sería el más adecuado.
} 
extienda en explicaciones que su intuición puede perfectamente suplir. Los diccionarios monolingües de uso común cuentan, por lo tanto, implícitamente con ese saber idiomático que se supone interiorizado por sus destinatarios y que ahorra hacer explícitas de manera regular las propiedades sintáctico-semánticas de las piezas léxicas, así como las reglas que gobiernan su combinatoria y actualización en el discurso.

Frente a los repertorios comunes, los diccionarios didácticos tienen, en principio, como destinatario potencial a un tipo de hablante que, lejos de tener la competencia del usuario nativo medio, puede presentar diversas lagunas en el conocimicnto activo y pasivo de la lengua. En cualquier caso, se trata de un destinatario al que, metodológicamente, se le debe presuponer un determinado grado de incompetencia que impedirá dar por «sabidas» muchas de las informaciones habitualmente obviadas para el hablante nativo ideal. Naturalmente, no son iguales las carencias y, por lo tanto, las necesidades de aprendizaje de un escolar que perlecciona el uso de su lengua materna que las de un extranjero. Por lo tanto, dentro de la lexicografía didáctica habría que distinguir dos orientaciones bien diferenciadas: la que tiene como objetivo servir de apoyo a la enseñanza de las Icnguas matcrnas y la que se destina al aprendizaje de segundas lenguas. En ambos casos, no obstante, el diccionario se concibe como un instrumento fundamental en el proceso de enseñanza/aprendizaje de lenguas; de ahí lo acertado de la denominación genérica «diccionario didáctico» o «pedagógico"; aunque pueda parecer redundante.

En clecto, la expresión compleja «diccionario didáctico», como ya vio $\mathrm{H}$. Hernández (1998), resultaría una denominación poco afortunada si no se tuviera en cuenta el papel de estas obras en el proceso docente y discente. Pues, en efecto, «la naturaleza didáctica del diccionario, de cualquier tipo de diccionario» es un principio indiscutible y comúnmente aceptado por la teoría lexicográfica (Dubois, 1970; Rey-Debove, 1971; Alvar Ezquerra, 1982) y hasta por el sentido común: todo diccionario enseña. Sin embargo, aunque los diccionarios son, por su propia naturaleza, obras didácticas, no todos persiguen los mismos objetivos ni cstán pensados para el mismo público. Nuestra propuesta para la denominación de los diccionarios monolingües especialmente concebidos para la enseñanza de Ienguas (matcrnas o extranjeras) sería la siguiente:

Proponemos, pues, utilizar la denominación «Diccionario didáctico» como ctiquela genérica para designar a los diccionarios especialmente diseñados para los usuarios que se encuentran en el proceso de aprendizaje de una lengua. 


\section{"DICCIONARIO DIDÁCTICO"}

(Concebido para facilitar el proceso de enseñanza/aprendizaje de lenguas)

"DICCIONARIO ESCOLAR"

(Enseñanza/aprendizaje de la lengua materna)
"DICCIONARIO DE APRENDIZAJE"

(Enseñanza/aprendizaje de la lengua extranjera)

Proponemos, así mismo, conservar la denominación «Diccionario escolar», cuyo uso se encuentra ya bastante extendido entre especialistas y profanos, para referirnos a aquella variedad del diccionario didáctico que tiene como destinatario potencial al escolar que, en los diversos ciclos de la enseñanza no universitaria, aprende a perfeccionar su lengua materna. Finalmente, con la expresión «Diccionario de aprendizaje» se podrían denominar los diccionarios didácticos siempre monolingües - concebidos para usuarios no nativos; denominación que, por otro lado, se emplea en distintas lenguas como calco del original inglés «Learner's dictionary» (Schafroth, 1998: 97 y sigs.).

Pero por encima de las cuestiones terminológicas, lo importante, en última instancia, es el reconocimiento de la diferente orientación que el tipo de destinatario imprime a los denominados diccionarios «didácticos». Esta orientación afecta a la totalidad de la estructura de estas obras; es decir, tanto a la macroestructura - cuyo diseño se adaptará a las necesidades del aprendiz, graduando la cantidad y calidad del léxico inventariado- como a la microestructura — donde habrá de tenerse en cuenta de manera especial las características concretas del destinatario para la selección y disposición del conjunto de informaciones que componen el artículo- Tal y como viene reconociendo la teoría lexicográfica (M. Rundell, 1998; Schafroth, 1998), los rasgos que diferencian un diccionario monolingüe de tipo didáctico de otro común se manifiestan principalmente en los siguientes aspectos:

- control del vocabulario

- mayor presencia de información gramatical o sintáctico semántica

- tipo de ejemplificación

- tratamiento de las unidades fraseológicas, especialmente de las colocaciones 


\section{Los diccionarios didácticos del español: el diccionario escolar}

Por lo que se refiere a nuestro país ${ }^{4}$, la confección de diccionarios no parece haber tenido en cuenta ni la naturaleza del destinatario de la obra lexicográfica ni sus necesidades específicas hasta fechas relativamente recientes. Aunque, desde hace casi dos décadas, algunos diccionarios hayan utilizado la etiqueta «escolar» (Hernández, 1989; Martínez Marín, 1991) a modo de reclamo para posicionarse en un mercado, hasta entonces, de baja competencia. La mayoría de los diccionarios, supuestamente escolares, que se publican en España con anterioridad a la década de los 90 presentan numerosas deficiencias, entre las cuales habría que destacar:

- La inadecuada selección del corpus repertoriado.

- La falta de precisión o excesiva generalidad en la formulación de las definiciones, que suelen presentar, en ocasiones, casos de circularidad o de «pistas perdidas».

- Ausencia de un criterio uniforme en la ordenación de las acepciones, así como en la ubicación de los elementos fraseológicos.

- Graves insuficiencias en el apartado de la información gramatical; especialmente aquella que incide más directamente en los aspectos productivos y normativos.

- Escasa o nula presencia de ejemplos que orienten en el uso y favorezcan, por tanto, la función codificadora del diccionario.

- Escasa atención a los aspectos pragmáticos y sociolingüísticos del léxico.

Las conclusiones que en su libro de 1989 (267-264) ofrecía H. Hernández sobre la calidad de los diccionarios destinados al uso escolar, venían a confirmar, a partir del análisis interno de estas obras, sus múltiples carencias y, en suma, la falta de rigor y el descuido con que habían sido confeccionadas la mayor parte de ellas. A juicio de Martínez Marín (1991: 60), tantas deficiencias tenían origen «en el empleo de una metodología anticuada» y en la falta de objetivación de un modelo de diccionario escolar que no fuese deudor de diccionarios generales anteriores. Un modelo de diccionario didáctico para uso escolar basado en un análisis previo de las necesidades de sus destinatarios.

\footnotetext{
${ }^{4}$ En España, es en la década de los 90 cuando se empieza a animar el panorama editorial con la aparición de diccionarios que presentan como novedad la selección del tipo de destinatario y el carácter funcionalmente orientado de su cometido didáctico. Cf. H. Hernández (1996) y (1998). Aparte de la eclosión de una lexicografía de orientación escolar renovada, la década de los 90 nos ha deparado otras novedades lexicográficas ausentes hasta entonces del panorama español, tales como: el Imaginario. Diccionario en imágenes para niños (1992), el VOX Diccionario ideológico de la lengua española (1995), o cl Diccionario para la enseñanza de la lengua española (1996), que son algunas muestras de tipos de obras incxistentes en el mercado editorial español.
} 
A pesar de los logros alcanzados en los últimos tiempos, la investigación de base en el sector de la lexicografía de orientación pedagógica presenta todavía importantes lagunas; como por ejemplo: «Establecer la tipología de los usuarios, determinar cuáles son sus necesidades y cuáles las destrezas que deben desarrollar» (Hernández, 1998: 50); sin olvidarnos de la necesidad del seguimiento del efecto que los llamados «diccionarios didácticos» tienen sobre el aprendizaje del vocabulario por parte de sus destinatarios por excelencia: la población escolar. Seguimiento en el que, según nuestra opinión, debería involucrarse también al colectivo docente en tanto que copartícipe en el proceso de enseñanza/aprendizaje de lá lengua.

En lo que sigue trataremos de evidenciar la actitud de alumnos y profesores frente al diccionario, exponiendo los resultados de una encuesta en la que intentamos recabar la opinión de ambos colectivos acerca de la frecuencia de uso y del aprovechamiento de las utilidades de esas obras fundamentales para el desarrollo de la competencia léxica e idiomática que son los diccionarios de orientación pedagógica.

Somos conscientes de que las encuestas no son fiables al cien por cien. Pero, aun concediendo a los datos que de ellas se desprenden un discreto valor aproximativo acerca del fenómeno que se pretende objetivar, sus resultados son, hoy por hoy, el único medio de que disponemos para conocer la opinión de los destinatarios del producto lexicográfico.

En el planteamiento de la encuesta hemos tratado de evitar los defectos detectados en tentativas similares llevadas a cabo con anterioridad por otros investigadores. Así, por ejemplo, ante la falta de homogeneidad que Calderón Campos (1994: 23) observa en algunas encuestas de esta índole que no tienen en cuenta la naturaleza de los distintos grupos de usuarios, en nuestro caso hemos distinguido, por un lado, el colectivo de los estudiantes y el de los profesores y, por otro, el nivel de escolarización de aquéllos y el ciclo o nivel en el que imparten la docencia en cl caso de los profesores. También hemos prescindido de las preguntas de tipo abierto o excesivamente generales.

Como puede observarse en los apéndices 1 y 2 de este trabajo, para evitar una cxcesiva atomización en las contestaciones que dificultara el ulterior procesamiento de los datos, el cuestionario fue estructurado en conjuntos cerrados, compuestos por varias opciones que se presentaban a los encuestados como posibles respuestas entre las que elegir una o varias. Si bien, en aquellos apartados donde era posible, se rescrvó una casilla para otros/as aspectos/ respuestas no presentes en cl listado. 
Finalmente, ei esquema de la encuesta quedó estructurada de la siguiente mancra:

1. Un primer bloque destinado a recabar los datos para la identificación de los alumnos encuestados (nombre, edad, curso), un mínimo encuadre sociológico (a través de las profesiones de los padres) y, al tratarse de una comunidad con dos lenguas ofïciales, la lengua materna del alumno (el español o la variedad del catalán que se usa en la Comunidad valenciana: el valenciano).

2. Un segundo bloque donde se introducen las preguntas relativas al uso actual del diccionario: ¿Qué diccionario? - título, editorial- ¿Quién recomienda o aconseja su compra? ¿Se ha utilizado algún otro diccionario anteriormente?

3. Un tercer bloque en el que se intenta detectar, por un lado, la frecuencia con la que el escolar acude al diccionario para resolver sus dudas y, por otro, de dónde procede su adiestramiento en el uso de esta obra consulta.

4. En último lugar, un cuarto bloque, dividido en tres subapartados ${ }^{5}$, donde se persigue averiguar:

- Para qué utilizan los encuestados sus diccionarios.

- Qué defectos o carencias, desde el punto de vista de sus usuarios, presentan los diccionarios que normalmente utilizan.

- Finalmente, como pregunta abierta, se invita a los encuestados a que hagan una valoración positiva de alguna de las características del diccionario que usan actualmente.

El modelo de encuesta que se pasó al colectivo docente es una adaptación del anteriormente descrito. Se modificaron los apartados relativos al encuadre socioprofesional del encuestado (Apartados 1 y 2 de la cncuesta), pero conservamos cl resto de los bloques de preguntas con las mínimas modifícaciones para que cl contraste entre la opinión de alumnos y profesores se pudiera hacer sobre la misma base de comparación.

\section{La comunidad escolar ante el diccionario: resultados de una encuesta}

En un trabajo anterior nos planteamós pulsar la opinión de los escolares a través

\footnotetext{
${ }^{5}$ Los blogues de respuestas incluídas en los subapartados 4.1 y 4.2 de la encuesta fueron elaborados teniendo en cuenta tanto los distintos tipos de información que suele proporcionar el artículo estándar de un diccionario escolar, como los defectos o carencias que la crítica Iexicográfica y la intuición de los usuarios scñalan como más comunes en este tipo de obras (Azorín Fernández, 1998).
} 
de una encuesta ${ }^{6}$ sobre el uso -utilidades, deficiencias, etc.- de los diccionarios que les servían de complemento en el aprendizaje de su lengua materna (Azorín Fernández, 1998). En el presente artículo intentaremos completar el panorama que ofrecíamos en aquella ocasión contrastándolo con el que muestran los resultados de otra encuesta que, sobre el mismo tenor, realizamos a un grupo representantivo de los profesores ${ }^{7}$ que tienen a su cargo la enseñanza de la lengua española en los tres niveles en que se divide actualmente el sistema educativo.

\subsection{Frecuencia de uso y fuente de aprendizaje}

A través de la encuesta a los alumnos, pudimos comprobar, entre otras cosas, que la mayoría de los informantes reconocían estar utilizando un diccionario de lengua y haber utilizado otros en cursos anteriores como puede apreciarse en el cuadro siguiente:

\begin{tabular}{|l|l|l|l|l|l|}
\hline \multicolumn{5}{|c|}{ USO DEL DICCIONARIO } \\
\hline \multicolumn{3}{|c|}{ USO ACTUAL } & \multicolumn{3}{c|}{ USO ANTERIOR } \\
\hline Primaria & ESO & COU & Primaria & ESO & COU \\
\hline $97 \%$ & $92 \%$ & $94 \%$ & $76 \%$ & $75 \%$ & $82 \%$ \\
\hline
\end{tabular}

Pero el hecho de reconocer que se está usando algún diccionario no es, en absoluto, indicativo del grado de familiaridad de los escolares con este tipo de obras; pues al tratarse de un instrumento de consulta y no de un manual o de un

\footnotetext{
${ }^{6}$ Las encuestas fueron aplicadas durante el curso escolar 1996-97 y 1997-98 a tres grupos de escolares de enseñanza no universitaría de diversos centros (públicos y privados) de Alicante y su provincia, pertenecientes a los siguientes ciclos y niveles educativos: Un grupo de enseñanza primaria; concretamente de $7^{\circ}$ de EGB, de distintos centros públicos y privados de Alicante y su provincia (652 cncuestados).

a) Un grupo de secundaria; de $3^{\circ}$ de ESO También de varios centros y poblaciones distintas (571 encuestados).

b) Un grupo de estudiantes de COU Igualmente de centros y procedencia local diversos (302 encuestados).

${ }^{7}$ Las encuestas al colectivo docente se llevaron a cabo durante el curso escolar 1998-1999. Logramos recabar información de un total de 264 profesores de enseñanza no universitaria, pertenecientes a distintos centros, públicos y privados, de Alicante y su provincia. La cuota de participación por niveles educativos fue la siguiente:

a) Grupo de profesores de enseñanza primaria: 115 participantes.

b) Grupo de profesores de Enseñanza Secundaria (ESO): 77 participantes.

c) Grupo de profesores de Bachillerato: 72 participantes.

El modelo de encuesta puede verse en los Apéndices 1 y 2 que se insertan al final de este trabajo.
} 
libro de texto cuya lectura sea obligatoria, la frecuencia de uso puede llegar a ser extremadamente variable si descendemos a los casos concretos. En nuestra encuesta preveíamos hasta 4 tipos distintos de posibilidades en la frecuencia de uso ${ }^{8}$ del diccionario por parte de los escolares entrevistados:

- TIPO 1: supone un elevado grado de integración del diccionario en los hábitos de estudio del escolar, que es capaz de utilizarlo como instrumento de trabajo cotidiano para resolver sus dudas cuando la ocasión lo requiera.

- TIPO 2: cl uso del diccionario aparece ligado exclusivamente a la reflexión metalinguiística que el alumno desarrolla cuando trabaja algún aspecto de la estructura de su lengua.

- TIPO 3: el diccionario, todavía más que en el caso anterior, no se logra desgajar de las tareas escolares de tipo rutinario. El alumno no ha conseguido interiorizar de ninguna manera el hábito de acudir al diccionario para resolver sus dudas y sólo se acerca a él a instancias del profesor.

- TIPO 4: supone el reconocimiento por parte de los encuestados de no haber adquirido hábito alguno —ni siquiera condicionado- en el uso del diccionario?.

\begin{tabular}{|c|c|c|c|}
\hline \multicolumn{4}{|c|}{ FRECUENCIA DE USO } \\
\hline TIPO & PRIMARIA & ESO & COU \\
\hline TIPO 1 & $49 \%$ & $45 \%$ & $52 \%$ \\
\hline TIPO 2 & $18 \%$ & $12 \%$ & $8 \%$ \\
\hline TIPO 3 & $14 \%$ & $15 \%$ & $3 \%$ \\
\hline TIPO 4 & $11 \%$ & $17 \%$ & $25 \%$ \\
\hline TIPO 5 & $8 \%$ & $11 \%$ & $12 \%$ \\
\hline
\end{tabular}

Si alguna reflexión se impone ante los datos que acabamos de presentar es la que nos lleva a reafirmarnos en el convencimiento de que el uso productivo del diccionario sólo se adquiere como resultado de un aprendizaje que ha de comenzar lo más tempranamente posible. No es extraño, por tanto, que en el último curso de

${ }^{8}$ En la encuesta distinguíamos hasta cinco tipos de frecuencia de uso:

- Tipo I: Lo tengo siempre a mano cuando hago los deberes.

- Tipo 2: Sólo lo uso cuando hago los deberes de lengua.

- Tipo 3: Sólo lo uso cuando me lo manda el profesor.

- Tipo 4, Lo uso muy poco.

- Tipo 5: Otros/No contesta.

"No comentamos los casos de frecuencia de tipo 5, puesto que o bien se trata de variantes de los otros cuatro o corresponden a respuestas en blanco por parte de los encuestados. 
la enseñanza no universitaria — donde se supone que los hábitos adquiridos en las anteriores etapas se consolidan de alguna manera- se den los porcentajes más elevados tanto del uso sistemático y consciente del diccionario en tanto que instrumento de consulta (TIPO 1), como del que hace referencia al muy escaso o nulo aprovechamiento de este útil de trabajo (TIPO 4). Y que, al mismo tiempo, sea también en COU donde los usos dirigidos o más mediatizados por la dinámica docente o por la inseguridad en el dominio de la propia lengua, alcancen menores indices de representación (TIPOS 2 y 3 ).

Podemos concluir, pues, que cuanto más temprano sea el adiestramiento del individuo en el manejo del diccionario, tanto mayor será su integración como útil de trabajo en las tareas escolares y más se potenciará el hábito de recurrir a su consulta en un futuro para resolver todo tipo de dudas sobre el uso del idioma. Sin embargo, como también se desprende de los resultados de nuestra encuesta, la enseñanza del manejo del diccionario no parece estar generalizada en el ámbito escolar. De las tres posibilidades que se ofrecían a los encuestados a propósito de la pregunta: ¿Quién te ha enseñado a manejar el diccionario?:

- TIPO 1: el profesor, en clase.

- TIPO 2: en casa, con mis padres, hermanos, etc.

- TIPO 3: de manera autodidacta (con/sin las instrucciones de uso del diccionario).

Los resultados obtenidos fueron los siguientes:

\begin{tabular}{|c|c|c|c|}
\hline \multicolumn{4}{|c|}{ APRENDIZAJE DEL USO DEL DICCIONARIO } \\
\hline TIPO & PRIMARIA & ESO & COU \\
\hline TIPO 1 & $42 \%$ & $46 \%$ & $43 \%$ \\
\hline TIPO 2 & $29 \%$ & $16 \%$ & $12 \%$ \\
\hline TIPO 3 & $29 \%$ & $35 \%$ & $43 \%$ \\
\hline NO RESPONDE & $0 \%$ & $3 \%$ & $2 \%$ \\
\hline
\end{tabular}

El profesor, cn clase, como se puede observar, es la fuente de aprendizaje que alcanza mayor representatividad desde el punto de vista estadístico. Sin embargo, pese a ser ésta la principal vía de iniciación en el uso del diccionario, nos parece inconccbible que todavía más del $50 \%$ de los encuestados manifiesten haber comenzado a familiarizarse con el diccionario y su manejo fuera del ámbito escolar; esto es, a partir de las otras tres fuentes que mostrábamos como posibles.

En la encuesta realizada al colectivo docente los resultados de este apartado son sensiblemente diferentes. En general, los profesores de los distintos niveles de enseñanza no universitaria reclaman la responsabilidad de adiestrar a sus alumnos en el manejo del diccionario, aunque en la práctica docente no se logre plenamente 
este objetivo. A la pregunta de ¿Quién debe enseñar a los alumnos el uso del diccionario?, la respuesta de los profesores fueron las siguientes:

\begin{tabular}{|c|c|c|c|}
\hline \multicolumn{4}{|c|}{ ENSEÑANZA DEL USO DEL DICCIONARIO } \\
\hline TIPO & PRIMARIA & ESO & BACH./COU \\
\hline TIPO 1 & $69 \%$ & $83 \%$ & $89 \%$ \\
\hline TIPO 2 & $30 \%$ & $16 \%$ & $8 \%$ \\
\hline TIPO 3 & $1 \%$ & $1 \%$ & $3 \%$ \\
\hline NO RESPONDE & $0 \%$ & $0 \%$ & $0 \%$ \\
\hline
\end{tabular}

\subsection{Finalidad del uso desde el punto de vista de los escolares}

Una de las consecuencias de la falta de adiestramiento en el uso del diccionario scrá precisamente el escaso rendimiento que los escolares obtienen de este instrumento de consulta. Como veremos a continuación, de las múltiples posibilidades que el diccionario brinda, la mayoría de los estudiantes encuestados limitan sus consultas a un pequeño número de funciones.

En cl cuadro siguiente recogemos los resultados del apartado 4.1 de la encuesta a los alumnos, donde se puede apreciar en términos porcentuales el orden en las preferencias de búsqueda de información de nuestros informantes. Antes de presentar los datos nos gustaría señalar que en las cinco primeras funciones que aparecen en el listado se concentran el $68 \%$ de las consultas de los alumnos de Primaria, cl $72 \%$ de los de ESO y el $80 \%$ de los de COU También es de destacar el hecho de que los tres colectivos de estudiantes coincidan en señalar como objeto prelerente de sus consultas:

- la búsqueda del significado de las palabras «que no entiendo»

- comprobar cómo se escribe una palabra

- la búsqueda de sinónimos y antónimos

que constituyen, con diferencia, las tres finalidades básicas a las que los escolares destinan sus diccionarios. Sólo estas tres funciones suponen el $51 \%$ de las consultas para los alumnos de Primaria, el $55 \%$ para los de ESO y el $67 \%$ para los de COU: 


\begin{tabular}{|c|c|c|c|c|c|}
\hline \multicolumn{6}{|c|}{ ENCUESTA ALUMNOS } \\
\hline \multicolumn{2}{|l|}{ PRIMARIA } & \multicolumn{2}{|l|}{ ESO } & \multicolumn{2}{|l|}{$\mathrm{COU}$} \\
\hline Tipo & $\%$ & Tipo & $\%$ & Tipo & $\%$ \\
\hline $\begin{array}{c}\text { "a" } \\
\text { (significado) } \\
\end{array}$ & 24 & $\begin{array}{c}\text { "a" } \\
\text { ( significado) } \\
\end{array}$ & 25 & $\begin{array}{c}\text { "a" } \\
\text { (significado) }\end{array}$ & 29 \\
\hline $\begin{array}{c}\text { "b" } \\
\text { (ortografía) }\end{array}$ & 16 & $\begin{array}{c}\text { "b" } \\
\text { (ortografía) }\end{array}$ & 16 & $\begin{array}{c}\text { "b" } \\
\text { (ortografía) }\end{array}$ & 19 \\
\hline $\begin{array}{c}\text { "k" } \\
\text { (sinón-/antón-) }\end{array}$ & 11 & $\begin{array}{c}\text { "k" } \\
\text { (sinón-/antón-) }\end{array}$ & 14 & $\begin{array}{c}\text { "k" } \\
\text { (sinón-/antón-) }\end{array}$ & 19 \\
\hline $\begin{array}{c}\text { "i" } \\
\text { (régimen verbal) }\end{array}$ & 10 & $\begin{array}{c}\text { "I" } \\
\text { (fraseología) }\end{array}$ & 10 & $\begin{array}{c}\text { "i" } \\
\text { (régimen verbal) }\end{array}$ & 8 \\
\hline $\begin{array}{c}\text { "j" } \\
\text { (pronunciación) }\end{array}$ & 7 & $\begin{array}{c}\text { "i" } \\
\text { (régimen verbal) }\end{array}$ & 10 & $\begin{array}{c}\text { "d" } \\
\text { (cat. gramatical) }\end{array}$ & 8 \\
\hline $\begin{array}{c}\text { "d" } \\
\text { (cat. gramatical) }\end{array}$ & 7 & $\begin{array}{c}\text { "e" } \\
\text { (ejemplos de uso) }\end{array}$ & 7 & $\begin{array}{c}\text { "l" } \\
\text { (fraseología) }\end{array}$ & 8 \\
\hline $\begin{array}{c}\text { "l" } \\
\text { (fraseología) } \\
\end{array}$ & 6 & $\begin{array}{c}\text { "d" } \\
\text { (cat. gramatical) }\end{array}$ & 6 & $\begin{array}{c}\text { "e" } \\
\text { (ejemplos de uso) }\end{array}$ & 5 \\
\hline $\begin{array}{c}\text { "l" } \\
\text { (nivel lengua) }\end{array}$ & 5 & $\begin{array}{c}\text { "h" } \\
\text { (número) }\end{array}$ & 3 & $\begin{array}{c}\text { "j" } \\
\text { (pronunciación) }\end{array}$ & 3 \\
\hline $\begin{array}{c}\text { "c" } \\
\text { (ejemplos de uso) }\end{array}$ & 5 & $\begin{array}{c}\text { "j" } \\
\text { (pronunciación) }\end{array}$ & 3 & $\begin{array}{c}\text { "d" } \\
\text { (cat. gramatical) }\end{array}$ & 2 \\
\hline $\begin{array}{c}\text { "lh" } \\
\text { (número) }\end{array}$ & 5 & $\begin{array}{c}\text { "P" } \\
\text { (nivel lengua) }\end{array}$ & 3 & $\begin{array}{c}\text { "h" } \\
\text { (número) }\end{array}$ & 2 \\
\hline $\begin{array}{c}\text { "g" } \\
\text { (género ) }\end{array}$ & 4 & $\begin{array}{c}\text { "g" } \\
\text { (género) }\end{array}$ & 2 & $\begin{array}{c}\text { "m" } \\
\text { (otros) }\end{array}$ & 2 \\
\hline $\begin{array}{c}\text { "m" } \\
\text { (otros) }\end{array}$ & 1 & $\begin{array}{l}\text { "m" } \\
\text { (otros) }\end{array}$ & 2 & $\begin{array}{c}\text { "P" } \\
\text { (nivel lengua) }\end{array}$ & 1 \\
\hline
\end{tabular}

Los tres grupos de alumnos encuestados, como acabamos de mostrar, se limilan a explotar preferentemente tres de las doce finalidades que proponíamos. Se observa además que, a medida que avanza el nivel de escolarización de los alumnos, más acusada es la tendencia a restingir el uso del diccionario a estas tres funciones.

A mayor distancia de las que hemos visto, se sitúan las siguientes tres utilidades que se destacan en nuestra encuesta; en este caso, no del todo coincidentes entre los distintos grupos de escolares entrevistados.

Los alumnos de Primaria parecen decantarse claramente por los aspectos normativos de la pronunciación (ortología), por la ortografía del acento y, 
finalmente, por la gramática; puesto que declaran destinar el $10 \%$ de sus consultas a comprobar tanto la acentuación de las palabras como su categoría gramatical, destinando un 7\% de las mismas a resolver dudas de pronunciación. Indagaciones que parecen tener como principal motivo la resolución de ejercicios escolares de aplicación de la teoría gramatical — caso del $10 \%$ destinado a recabar información sobre el status categorial de las palabras- y que, por tanto, refuerzan el aprendizaje de la gramática como materia escolar y no el de la lengua; o bien, tratan de afianzar el aprendizaje de la ortografía —-máxima preocupación, como ya hemos visto- entre los escolares. Las consultas sobre la pronunciación pueden estar dictadas por motivaciones normativas; por ejemplo, saber cuál es la correcta adaptación al castellano de un extranjerismo como el que se pone de muestra en la encuesta (bacon, beicon, bacón, etc.).

Los alumnos de COU y de ESO coinciden en señalar entre sus intereses:

- La ortografía del acento (8\% y $10 \%$, respectivamente)

- La frascología ( $8 \%$ y $10 \%$, respectivamente)

- Los ejemplos (5\% y 7\%, respectivamente).

Lo que supone ya un uso más diferenciado de las utilidades más básicas o de las centradas en los aspectos normativos de la escritura y de la pronunciación, que son los que predominan en Primaria.

La frascología, especialmente las combinaciones pluriverbales de carácter idiomático - véase el ejemplo que introducíamos en la encuesta-, parece ser uno de los aspectos de la lengua materna (o extranjera) que, por sus implicaciones culturales y por las dificultades que presenta de cara a su actualización en el discurso, necesita de una mayor atención por parte del diccionario escolar (Garrido Moraga, 1989; Martínez Marín, 1994, Santamaría Pérez, 1998; Ruiz Gurillo, 2000). La fraseología lïgura además, como en adelante veremos, entre los defectos del diccionario más unánimemente destacados por los participantes en la encuesta.

En cl caso de los ejemplos, es también particularmente llamativo que sean los alumnos de ESO y COU los que más reclamen esta utilidad del diccionario claramente orientada a la codificación (Rey-Debove, 1971; Collignon y Glatigny, 1978). Puesto que, aunque el ejemplo cumpla ambas funciones - codificadora: al mostar las palabras en su contexto de uso, guiando así la futura producción de los consultantes; decodificadora: el ejemplo puede servir para completar la información que se proporciona en la definición o para ayudar a esclarecerla), el hecho de acudir al diccionario para buscar expresamente un ejemplo de uso implica, más bien, la búsqueda de un modelo que ayude a emplear, a usar una determinada palabra o unidad fraseológica de manera adecuada (Azorín FernándezMartínez Linares, 1998).

Muy escasa representación tiene, en todos los grupos, la búsqueda de información de carácter gramatical —a saber: categoría gramatical ("d"), el género 
("g") y el númcro ("h")—; aunque como ya referimos a propósito de la respuesta «d», son aquí también los alumnos de Primaria quienes más se interesen por estos aspectos, impelidos por una doble motivación, pragmática y metalingüística a la vez ${ }^{10}$

Llama la atención, así mismo, el escasísimo empleo del diccionario para establecer el nivel de uso de las unidades léxicas, que corresponde en nuestra encuesta al apartado «f». Curiosamente, son los alumnos de COU quienes menos recurren al diccionario para buscar este tipo de información - sólo un $1 \%$ de sus consultas se destinan a este propósito-, aumentando el interés por ella a medida que desciende el nivel de escolarización - $3 \%$ en ESO y $5 \%$ en Primaria-. Dato que pudiera, en principio, parecer contradictorio, ya que este tipo de uso - más orientado a explotar el potencial comunicativo que el dominio de la variación lingüística supone - sería más congruente con el grado de madurez idiomática de los alumnos de cursos superiores. Giuseppina Coviello (1987), on una experiencia similar a la nuestra llevada a cabo, en este caso, entre estudiantes universitarios, observa también que la búsqueda de información sobre niveles y registros de lenguáa no se encuentra entre los usos más destacados de los estudiantes. Sin embargo, en su encuesta, son los estudiantes de cursos más avanzados quienes se van a interesar en mayor medida por este tipo de información ${ }^{11}$. En nuestro caso, habría que pensar en que este bajísimo índice de uso puede deberse a la consolidación, en COU, de las consecuencias que la falta de un adecuado adiestramicnto en el uso de diccionario provoca a largo plazo. En COU observamos cómo «el distanciamiento entre el alumnado y el diccionario [...] sólo utilizado para la obtención de un tipo de información semántica normativista» (J. Fernández Vallejo, 1991: 244) alcanza sus máximas cotas; cuando, a juicio del anterior autor

\footnotetext{
1" Su menor desarrollo de la competencia comunicativa - lingǘstica y pragmática, se entiendecondicionaría el uso que estos alumnos hacen del diccionario. Es lógico, pues, que en Primaria $-\mathrm{y}$ también, aunque menor grado, en ESO-surjan más amenudo dudas sobre aspectos morfológicos género, inúmero, ctc. -que, en los estadios de enseñanza superiores, están ya casi superados (Candalija Reina-Marimón Llorca, 1998). Pero, también en estas primeras etapas, determinados usos están condicionados por la reflexión metalinguústica que, por ejemplo, supone la práctica escolar del análisis sintáctico o morfológico.

"Lat experiencia llevada a cabo por G. Coviello fue realizada entre dos grupos de estudiantes de Filología Francesa de la Universidad de Turín — de $1^{\circ}$ y $4^{\circ}$, concretamente-y se les inquiría sobre el uso del diccionario bilingüic - en su caso, francés-italiano e italiano-francés-y del monolingüe de su propia lengua materna. En general, los resultados que presenta esta autora, aunque nuestras encuestas no coincidan exactamente, muestran algunas similitudes muy significativas. Asi, por lo que respecta al uso del diccionario monolingüe, los alumnos de $1^{\circ}$ curso destacan las siguientes aplicaciones: a) la búsqueda del significado; b) resolver dudas ortográficas y c) la búsqueda de sinónimos. Mientras que los de $4^{\circ}$ curso se decantan por: a) la búsqueda del significado; b) sinónimos y c) dudas ortográficas. Posteriormente aparecerá la búsqueda de informaciones menos básicas, como por ejemplo las relacionadas - por este mismo orden de prelación- con: los neologismos y extranjerismos, las locuciones y cxpresiones idiomáticas, los niveles y registros de lengua, la etimología y la gramática.
} 
(1991: 249), «los textos lexicográficos constituyen un instrumento idóneo para el análisis de la lengua en términos generales y de forma especial para la diversidad lingüística»».

\subsection{Finalidad del uso desde el punto de vista de los profesores}

La encuesta a los profesores revela que la explotación de las utilidades del diccionario desde la perspectiva del ámbito docente concuerda, en parte, con los resultados que acabamos de examinar. El contraste de los datos anteriores con los que a continuación presentamos pone de manifiesto, sin necesidad de comentarios, los puntos de contacto entre las respuestas de los alumnos y las de los profesores:

\begin{tabular}{|c|c|c|c|c|c|}
\hline \multicolumn{6}{|c|}{ ENCUESTA PROFESORES } \\
\hline \multicolumn{2}{|l|}{ PRIMARIA } & \multicolumn{2}{|l|}{ ESO } & \multicolumn{2}{|l|}{ BACH./COU } \\
\hline Tipo & $\%$ & Tipo & $\%$ & Tipo & $\%$ \\
\hline $\begin{array}{c}\text { "a" } \\
\text { (buscar cl significado) }\end{array}$ & 23 & $\begin{array}{c}\text { "a" } \\
\text { (buscar el significado) }\end{array}$ & 22 & $\begin{array}{c}\text { "a" } \\
\text { (buscar el significado) }\end{array}$ & 22 \\
\hline $\begin{array}{c}\text { "b" } \\
\text { (ortografía) }\end{array}$ & 19 & $\begin{array}{c}\text { "b" } \\
\text { (ortografía) }\end{array}$ & 19 & $\begin{array}{c}\text { "b" } \\
\text { (ortografía) }\end{array}$ & 17 \\
\hline $\begin{array}{c}\text { "k" } \\
\text { (sinónimos/antónimos) }\end{array}$ & 17 & $\begin{array}{c}\text { "k" } \\
\text { (sinónimos/antónimos) }\end{array}$ & 18 & $\begin{array}{c}\text { "k" } \\
\text { (sinónimos/antónimos) }\end{array}$ & 15 \\
\hline $\begin{array}{c}\text { "d" } \\
\text { (cat. gramatical) }\end{array}$ & 8 & $\begin{array}{c}\text { "e" } \\
\text { (ejemplos de uso) }\end{array}$ & 7 & $\begin{array}{c}\text { "l" } \\
\text { (fraseología) }\end{array}$ & 10 \\
\hline $\begin{array}{c}\text { "e" } \\
\text { (cjemplos de uso) }\end{array}$ & 7,5 & $\begin{array}{c}\text { "d" } \\
\text { (cat. gramatical) }\end{array}$ & 7 & $\begin{array}{c}\text { "d" } \\
\text { (cat. .gramatical) }\end{array}$ & 7 \\
\hline $\begin{array}{c}\text { "J" } \\
\text { (frascología) }\end{array}$ & 6 & $\begin{array}{c}\text { "l" } \\
\text { (fraseología) }\end{array}$ & 6 & (régimen verbal) & 6 \\
\hline $\begin{array}{c}\text { "g" } \\
\text { (género) }\end{array}$ & 5 & $\begin{array}{c}\text { "g" } \\
\text { (género ) }\end{array}$ & 5 & $\begin{array}{c}\text { "e" } \\
\text { (ejemplos de uso) }\end{array}$ & 5 \\
\hline $\begin{array}{c}\text { "Ih" } \\
\text { (número) }\end{array}$ & 5 & $\begin{array}{c}\text { "h" } \\
\text { (número) }\end{array}$ & 5 & $\begin{array}{c}\text { "g" } \\
\text { (género) }\end{array}$ & 5 \\
\hline $\begin{array}{c}\text { "i" } \\
\text { (régimen verbal) }\end{array}$ & 3 & $\begin{array}{c}\text { "j"” } \\
\text { (pronunciaciôn) }\end{array}$ & 4 & $\begin{array}{c}\text { "p" } \\
\text { (niveles y registros) }\end{array}$ & 5 \\
\hline $\begin{array}{c}\text { “j”" } \\
\text { (pronunciación) }\end{array}$ & 3 & $\begin{array}{c}\text { "i" } \\
\text { (régimen verbal) }\end{array}$ & 3,5 & $\begin{array}{c}\text { "j" } \\
\text { (pronunciación) }\end{array}$ & 4,5 \\
\hline
\end{tabular}




\begin{tabular}{|c|c|c|c|c|c|}
\hline $\begin{array}{c}\text { "f" } \\
\text { (niveles y registros) }\end{array}$ & 2 & $\begin{array}{c}\text { "f" } \\
\text { (niveles y registros) }\end{array}$ & 2,5 & $\begin{array}{c}\text { "h" } \\
\text { (número) }\end{array}$ & 2,5 \\
\hline $\begin{array}{c}\text { "m" } \\
\text { (otros) }\end{array}$ & 1,5 & $\begin{array}{c}\text { "m" } \\
\text { (otros) }\end{array}$ & 1 & $\begin{array}{c}\text { "m" } \\
\text { (otros) }\end{array}$ & 1 \\
\hline
\end{tabular}

Así, por ejemplo, comprobamos que, independientemente del nivel en el que se impartal la docencia, los profesores reconocen dirigir las consultas de sus alumnos hacia la obtención de los tres tipos de información que aquéllos ponían también a la cabera de sus preferencias. De manera que, en este caso, las tres primeras finalidades de uso del diccionario continúan siendo:

- averiguar el significado de las unidades léxicas

- la comprobación de la ortografía

- la obtención de sinónimos y antónimos

Si bien en este caso, los profesores conceden más importancia relativa al uso del diccionario con finalidades ortográficas y a la búsqueda de sinónimos/antónimos en detrimento del resto de las funciones. Es importante señalar que, al igual que sucedía con los alumnos, los profesores tienden a concentrar en estas tres utilidades básicas el uso dirigido de sus discípulos, puesto que en ellas recae el 59\% de las preferencias del profesorado de Primaria y ESO y el $54 \%$ del de Bachillerato/COU. Estas coincidencias vienen a demostrar que, en buena medida, el comportamiento de los alumnos refleja, como era previsible, las pautas de uso del diccionario que han ido adquiriendo a su paso por los distintos ciclos de la enseñanza no universitaria.

Las siguientes tres funciones que se destacan entre el colectivo docente, aunque coinciden en general con las ya puestas de relieve por los alumnos, no ocupan exactamente el mismo orden de prelación. Según los resultados de la encuesta, los prolesores de Bachillerato/COU sitúan la búsqueda de las unidades fraseológicas entre los tipos de información con mayor importancia relativa (10\%) dentro del conjunto propuesto; mientras que para los de Primaria y ESO esta función queda relegada a la sexta posición (6\% en ambos casos), tras la información sobre la calcgoría gramatical ( $8 \%$ y $7 \%$, respectivamente) y los ejemplos de uso $(7,5 \%$ y $7 \%$ ). Recordemos que para los alumnos de ESO y COU, el significado de las unidades fraseológicas era uno de los motivos principales de sus consultas al diccionario ( $10 \%$ y $8 \%$, respectivamente), no tanto para los de Primaria $(6 \%)$.

No debemos olvidar que la comprensión y, sobre todo, el uso correcto de las unidades fraseológicas es una de las dificultades, todavía no resueltas desde el punto de vista didáctico, a las que se enfrentan los estudiantes en el aprendizaje de su propia lengua. La poca atención que normalmente se presta al componente fraseológico en la programación de las actividades escolares, convierten al diccionario en el único recurso de que disponen los profesores para atender a la 
docencia de esta importante parcela de las lenguas. No es extraño, por tanto, que en los cursos superiores, éstos encaminen a sus discípulos hacia la consulta sistemática de los repertorios lexicográficos para obtener la información que precisan acerca de este tipo de unidades. Como viene reconociendo desde hace tiempo la teoría lexicográlica ${ }^{12}$, los diccionarios didácticos deben cuidar especialmente el tratamiento de la fraseología, tanto en lo que se refiere a su ubicación/presentación en la estructura del diccionario como a su descripción propiamente lingüística (categorización morlosintáctica, definición, condiciones de empleo, etc.).

En Primaria y ESO, como ya hemos dicho, los profesores anteponen la búsqueda de información gramatical a la fraseología. Sin embargo, el tipo de información al que dirigen los docentes las consultas de sus alumnos se circunscribe especialmente a averiguar la categoría gramatical de las unidades léxicas. El objetivo que se persigue en estos casos es resolver las dudas puntuales que se ie plantean al alumno en la práctica del análisis morfológico y/o sintáctico. La experiencia Ilcvada a cabo por Candalija-Marimón (1998) a propósito de la utilización del diccionario en la enseñanza de la gramática, vendría a demostrar que los alumnos prefieren recurrir al libro de texto para resolver sus dudas sobre el status categorial del léxico y sólo a instancias del profesor acaban consultando el diccionario para este mismo cometido. La explicación que estos mismos autores dan sobre este hecho es que el proceder de los alumnos se encuentra, en buena medida, propiciado por su incapacidad para decodificar adecuadamente las abreviaturas del diccionario, lo que nos remite directamente a la necesidad de revisar el metalenguaje descriptivo que se emplea en las obras lexicográficas destinadas al público escolar, cuyas deficiencias disuaden al alumno a la hora de accrcarse al diccionario para extraer este tipo de información. ${ }^{13}$ En cualquicr caso, pensamos que el papel de la gramática en los diccionarios didácticos de orientación escolar debe rcbasar el estricto cometido taxonómico que tradicionalmente se le

\footnotetext{
12 Esta es la opinión que, por poner un ejemplo de aplicación a la enseñanza de la lengua materna, sostiene Gaston Gross (1989-91: 179): «Comme, à l'heure actuelle, il n'y a pas des exercices scolaires portant systématiquement sur les phrases figgés, le lieu naturelle de leur recenscment est encore le (licionnaire. Il est possible qu'un élève, relativement avancé déjà dans l'apprentissage, soit incapable de décrypter ees expressions. Nous plaidons done pour quélles figurent Jargement dans les dicionnaires».

1.3 A juicio de Candalija-Marimón (1998), entre las disfunciones que presentan la mayoría de los diccionarios escolares en el cmpleo de las abreviaturas y de la terminología relacionada con la gramática se pueden citar: «la falta de unificación sobre cuáles son los términos gramaticales que deberían estar presentes como indicación [...]; los distintos criterios de clasificación dentro del glosario (¿debe ser indef. una abreviatura o debe ir unida a pronom. o a adj.?) [...]; la desproporción entre el número de abreviaturas gramaticales y aquellas que ofrecen otro tipo de información [...]; la no presencia de los términos gramaticales en la macroestructura del diccionario y finalmente la escasa atención que se concede a la información gramatical que presenta el diccionario en las instrucciones de uso» (en prensa, s.p.).
} 
atribuye y convertirse en el transfondo que ordene la descripción del significado de las piezas léxicas. ${ }^{14}$

Entre las seis funciones mejor situadas en las preferencias de los profesores destaca, por último, la búsqueda de ejemplos. En este caso son los docentes de Primaria $(7,5 \%)$ y ESO $(7 \%)$ quienes ponen de relieve la importancia de este tipo de información, ausente hasta hace bien pocos años de nuestros diccionarios ${ }^{15}$; mientras que los profesores de Bachillerato y COU la sitúan en los últimos puestos de la escala. Alumnos y profesores vienen a coincidir en este aspecto concreto del uso del diccionario, puesto que es en los ciclos inferiores (Primaria y ESO) donde se asume por ambas partes la necesidad de frecuentar los ejemplos de uso, pensamos que más a modo de patrones para orientar la producción que como complemento para la comprensión del significado que aporta la definición. En los cursos superiores esta necesidad es mucho menos perentoria, de ahí la falta de insistencia de los profesores en su consulta y el poco interés despierta en los estudiantes.

Queremos señalar, por último, que al igual que sucedía en el caso de los alumnos, la respuesta del colectivo docente hacia ciertas utilidades del diccionario es poco menos que testimonial. Así, la información sobre el género, el número, el régimen verbal o la pronunciación, a juzgar por los resultados de la encuesta, apenas despiertan el interés del profesorado. Del mismo modo, el recurso al diccionario para obtener información sobre las restricciones de uso en función del contexto y la situación de comunicación manifiesta uno de los índices más bajos en la prelación de los profesores.

\footnotetext{
it Esto mismo sugicre G. Gross (1989-91: 177) cuando afirma que las deficiones que encontramos en determinados diccionarios para escolares «mettent en jeu un certain nombre de proprietés syntacticosemantiques; le travail lexicographique consiste donc à donner les proprietés de définition de chacun de ces emplois» en el caso de las entradas polisémicas.

${ }^{15}$ Uno de los logros más destacados de la lexicografía española actual es la incorporación sistemática de ejemplos como complemento de la descripción del significado de las palabras; algo inusual en los diccionarios del español, tradicionalmente faltos — quizás por la influencia del DRAE - de esta parte fundamental de la microestructura de todo compendio lexicográfico. Hoy podemos decir que la llamada de atención del profesor Alvar Ezquerra, en el Congreso de la Lengua Española de Sevilla de 1992, sobre la necesidad de remediar este mal endémico de la lexicografía monolingüe del español, no ha caído en saco roto. En aquella ocasión, entre otras reformas urgentes, consideraba necesario que «los dicionarios del futuro contengan abundantes ejemplos, no como ornamentación, sino como modelos de uso de las palabras, como contextualización de lo que se dice en el artículo. La falta de ejemplos se achaca continuamente a nuestros diccionarios sin que se ponga un remedio eficaz, tal vez por comodidad -y economía de los editores-, tal vez por mantenimiento de una malhadada tradición» (Alvar Ezquerra, 1994: 634). El sector que más ha acusado esta positiva incorporación ha sido, precisamente, el del diccionario didáctico. Véase el análisis de las características más destacadas de la nueva lexicografía de orientación escolar en lengua española que hace M. Carmen Ávila Martín $(2000)$.
} 
En el cuadro que adjuntamos a continuación, puede apreciarse, de manera contrastiva, cuáles son las funciones del diccionario que realmente se explotan en el proceso de enseñanza/aprendizaje de la lengua española, según la opinión de los dos colectivos representados en nuestra encuesta. Hemos destacado sólo las que ocupan los seis primeros puestos en virtud de su importancia relativa dentro del conjunto de las doce utilidades que proponíamos en el cuestionario.

\begin{tabular}{|c|c|c|c|c|c|c|c|c|}
\hline \multicolumn{9}{|c|}{$\begin{array}{c}\text { USOS DEL DICCIONARIO } \\
\text { CUADRO COMPARATIVO ALUMNOS/PROFESORES }\end{array}$} \\
\hline \multicolumn{3}{|c|}{ PRIMARIA } & \multicolumn{3}{|l|}{ ESO } & \multicolumn{3}{|c|}{$\mathrm{COU}$} \\
\hline Tipo & $\%$ & $\begin{array}{r}\% \\
\text { Pr. }\end{array}$ & Tipo & $\begin{array}{l}\% \\
\text { Al. }\end{array}$ & $\begin{array}{l}\% \\
\text { Pr. }\end{array}$ & Tipo & $\begin{array}{l}\% \\
\text { Al. }\end{array}$ & $\begin{array}{r}\% \\
\text { Pr. }\end{array}$ \\
\hline $\begin{array}{c}\text { "a" } \\
\text { (significado) }\end{array}$ & 24 & 23 & $\begin{array}{c}\text { "a" } \\
\text { (significado) }\end{array}$ & 25 & 22 & $\begin{array}{c}\text { "a" } \\
\text { (significado) }\end{array}$ & 29 & 22 \\
\hline $\begin{array}{c}\text { "b" } \\
\text { (ortografía) }\end{array}$ & 16 & 19 & $\begin{array}{c}\text { "b" } \\
\text { (ortografía) }\end{array}$ & 16 & 19 & $\begin{array}{c}\text { "b" } \\
\text { (ortografía) }\end{array}$ & 19 & 17 \\
\hline (sinón-antón.) & 11 & 17 & $\begin{array}{c}\text { "k" } \\
\text { (sinón-antón.) }\end{array}$ & 14 & 18 & $\begin{array}{c}\text { "k" } \\
\text { (sinón-antón.) }\end{array}$ & 19 & 15 \\
\hline $\begin{array}{l}\text { "i"/"d" } \\
\text { (régimen verb/ } \\
\text { cat. gram.) }\end{array}$ & 10 & 8 & $\begin{array}{c}\text { "I"/ "e" } \\
\text { (iraseol./ejemplo } \\
\text { uso) }\end{array}$ & 10 & 7 & $\begin{array}{c}\text { "i"/"l" } \\
\text { (régimen } \\
\text { verb/frascol.) }\end{array}$ & 8 & 10 \\
\hline $\begin{array}{c}\text { "j"/ "c" } \\
\text { (pronuncia./ } \\
\text { cjemplos uso) }\end{array}$ & 7 & 7,5 & $\begin{array}{c}\text { "i" "d" "d" } \\
\text { (régimen verb/ } \\
\text { cat. gram.) }\end{array}$ & 10 & 7 & "d" & 8 & 7 \\
\hline $\begin{array}{l}\text { "d"/ "l" } \\
\text { (cat. gram./ } \\
\text { (raseol.) }\end{array}$ & 7 & 6 & $\begin{array}{l}\text { "e"/"l" } \\
\text { (ejemplo uso/ } \\
\text { fraseol) }\end{array}$ & 7 & 6 & $\begin{array}{c}\text { "I»/ "i" } \\
\text { (fraseol / } \\
\text { régimen verbal) }\end{array}$ & 8 & 6 \\
\hline
\end{tabular}

Los datos porcentuales que exhibe el cuadro anterior nos permiten avanzar, de mancra provisional, las siguientes conclusiones sobre el uso del diccionario en el ámbito escolar:

1.- Quc, a pesar de los notables progresos que se detectan en la lexicografía didáclica del español, cl diccionario no se halla todavía incardinado de manera plena en el proceso de enseñanza/aprendizaje de la lengua española en el ámbito escolar. Prueba de cllo es el escaso aprovechamiento que alumnos y profesores obtienen de este instrumento didáctico. 
2.- Que, dcbido en parte a las deficiencias que aún presentan algunos diccionarios y, sobre todo, a la falta de formación en su manejo, los escolares no alcanzan a explotar todas las posibilidades que, al menos en teoría, el diccionario les brinda. Por lo que el uso queda limitado en la mayoría de los casos a:

- Buscar el significado de las palabras.

- Comprobar la ortografía.

- La búsqueda de sinónimos y antónimos

3.- Que este uso, un tanto empobrecido y dependiente de los aspectos más mecánicos y gramaticalistas de la didáctica de las lenguas, está en buena medida propiciado por las pautas de consulta que reciben de sus profesores, como se desprende de las muchas coincidencias que hemos visto aparecer entre los distintos grupos de estudiantes y de docentes.

4.- Quc para lograr la plena integración del diccionario en la enseñanza de la lengua española como lengua materna, es absolutamente necesario implicar a los docentes en la tarea de dar a conocer, de enseñar paulatinamente el manejo y las posibilidades de obtener información que el diccionario brinda. Sólo así el diccionario llegará a ser esa herramienta útil que ayude al estudiante no sólo a cnfrentarse con mayor seguridad a las tareas escolares, sino también a adquirir el hábito de consultar el diccionario para dirimir las dudas que sobre el propio idioma le habrán de surgir a lo largo de su vida.

\section{Referencias bibliográficas:}

Alvar Ezquerra, M. (1982): «Función del diccionario en la enseñanza de la lengua», Revista de Bachillerato, $\mathrm{N}^{\circ} 22$, págs. 49-53.

Alvar Ezquerra, M. (1994): «La forma de los diccionarios a la luz del signo lingüístico», en $\mathrm{H}$. Hernández (ed.), Aspectos de lexicografía contemporánea, Barcelona, Biblograf, págs. 3-13.

Alvar Ezquerra, M. (1994): «El futuro de los diccionarios del español», Actas del Congreso de la lengua Española (Sevilla, 7-10 de octubre, 1992), Madrid, Instituto Cervantes.

Ávila Martín, M. C. (2000): El diccionario en el aula. Sobre los diccionarios escolares destinados a la enseñanza y aprendizaje del español como lengua materna, Granada, Universidad de Granada.

Azorín Fernándcz, D. y M. A. Martínez Linares (1998): «La definición lexicográfica: revisiones y propuestas», en J. A. de Molina Redondo y J. D. Luque Durán (eds.), Estudios de Lingüística General III, Granada, Universidad de Granada, págs. 1-10. 
Azorín Fcrnándicz, D. (1998): «¿Para qué usan el diccionario los escolares? Rellexiones a propósito de una encuesta», en Actas del Congreso Tendencias en la Lexicografía Española Actual, Huelva, 25-27 de Noviembre, 1998, (en prensal).

Calderón Campos, M. (1994): Sobre la elaboración de diccionarios monolingües de producción, Granada, Universidad de Granada.

Candalija Reina, J. A. y M. C. Marimón Llorca (1998): «La información gramatical en los diccionarios escolares: reflexiones a propósito de una encuesta sobrc el uso del diccionario», Actas del Congreso Tendencias en la Lexicografía Española Actual, Huelva, 25-27 de Noviembre, 1998, (en prensa).

Collignon, L. y M. Glatigny (1978): Les dictionnaires. Initiation à la lexicographie, París, Cedic.

Coviello, G. (1987): «1 dizionario oggi. Due gruppi di studenti messi a confronto su un «oggetto» molto discusso», Rassegna Italiana di Lingiiística applicata, XIX, págs. 109-129.

Dubois, J. (1970): «Dictionnaire et discours didactique», Langages, 19, págs. 3547.

Ettinger, S. (1982): «Formación de palabras y fraseología en la lexicografía», en G. Hacnsch et alii, La lexicografia, Madrid, Gredos, págs. 233-258.

Fcrnández Vallcjo, J. (1991): «La enseñanza de las variedades lingüísticas a través de los textos lexicográficos», Lenguaje y textos, 10, págs. 239-251.

Gallisson, R., (1983): «Image et ussage du dictionnaire chez des étudiants (en laguc) de niveau avancé», $E L A, \mathrm{~N}^{\circ} 49$, janvier-mars, págs. 5-88.

Garrido Moraga, A. (1989): «Fraseología y enseñanza», Revista de la Asociación Europea de Profesores de Español, XIX-XX, No 36-37, págs. 67-73.

Gross, G. (1989-1991): «Le dicionnaire et l'enseignement de la languc maternelle» en Hausmann et al., (1989-91), vol. II, págs. 174-180.

Haensch, G., Wolf., L., Ettinger, S. y Werner, R. (1982): La lexicografía. De la lingiiística teórica a la lexicografía práctica, Madrid, Gredos.

Hausmann, F. J., Reichmann, O. Wiegand, E. y Zgusta, L. (1989-1991): Wörterbucher/ Dictionaries/ Dictionnaires. Ein internationales Handbuch zur Lexikographiel An International Encyclopaedia of Lexicography/ Enciclopédie internationale de lexicographie, 3 vols, Berlin-New York, De Gruyter.

Hernández, H. (1989): Los diccionarios de orientación escolar. Contribución al estudio de la lexicografia monolingiie española, Tübingen, Max Niemeyer Vcrlag, Lexicographica Series Maior, 88.

Hernández, H. (1996): «La lexicografía didáctica: los diccionarios escolares del español en el último cuarto de siglo», Cuadernos Cervantes, $\mathrm{N}^{\circ} 11$, noviembre-diciembre, págs. 24-36. 
Hernández, H. (1998): «La lexicografía didáctica del español: aspectos históricos y críticos», en M. T. Fuentes Morán y R. Werner, Lexicografías iberorrománicas: problemas, propuestas y proyectos, Frankfurt am Main, Vervuert Verlag, 1998, págs. 49-79.

Maldonado, C. (1993): «Cómo elegir un diccionario escolar», Alacena, 17, págs. $12-13$.

Maldonado, C. (1998): El uso del diccionario en el aula, Madrid, Arco-Libros.

Martínez Marín, J. (1991): «Fraseología y diccionarios modernos del español», Voz y Letra, II-I, págs. 117-126.

Martínez Marín, J. (1992): «Los diccionarios escolares del español. Lo que son y lo que deberían ser», en I. Ahumada (ed.), Diccionarios españoles: contenidos y aplicaciones, Jaén, Seminario de Lexicografía Hispánica, Facultad de Humanidades, págs. 53-70.

Olarte Stampa, L. A Garrido Moraga (1984): «Diccionario y enseñanza (Aproximación a los diccionarios más usados en los niveles educativos)», Lingiaística Española Actual, $\mathrm{N}^{\circ}$ 41, págs. 21-28.

Rey-Debove, J. (1971): Étude linguistique et sémiotique des dictionnaires français contemporains, París-La Haya, Mouton.

Ruiz Gurillo, L. (2000): «Cómo integrar la fraseología en los diccionarios monolinguies», en G. Corpas (2000) (ed.): Las lenguas de Europa: estudios de fraseología, fraseografía y traducción, Granada, Editorial Comares.

Rundell, M. (1998): «Recent trends in english pedagogical lexicography», International Journal of Lexicography, vol. 11, Number 4, 1998, págs. 315342.

Santamaría Pérez, M. I. (1998): «Fraseología y diccionario: aproximación práclica», Actas del Congreso de Tendencias en la Lexicografía Española Actual, Huclva, Universidad de Huelva, 25-27 de noviembre, 1998.

Schafroth, E. (1998): «Consideraçôes sobre um dicionário de aprendizagem de língua portuguesa», en M. T. Fuentes Morán y R. Werner, Lexicografias iberorrománicas: problemas, propuestas y proyectos, Frankfurt am Main, Vervucrt Verlag, 1998, págs. 97-119.

\section{APÉNDICL 1}

\section{1.- DATOS DEL ALUMNO}

NOMBRE:

EDAD:

CURSO:

PROFESIÓN DEL PADRE: 


\section{2.- USO DEL DICCIONARIO: DATOS EXTERNOS}

- ¿Usas algún diccionario actualmente?

- ¿Recuerdas el título?

- ¿Recuerdas la editoral?

- ¿Quién te lo recomendó?

- El profesor

- Tus padres

- En la librería

- Un amigo

- Otros

- ¿Habías utilizado antes otro diccionario?

Sí

NO

- ¿Recucrdas el título?

- ¿Y la editorial?

\section{3.- USO DEL DICCIONARIO: FRECUENCIA Y APRENDIZAJE}

- ¿Con qué frecuencia usas el diccionario?

1. Lo lengo sicmpre a mano cuando hago los deberes

2. Sólo lo uso cuando hago los deberes de lengua

3. Sólo cuando me lo manda el profesor

4. Lo uso muy poco

5. Otros

- ¿Quién te ha enseñado a manejar el diccionario?

6. El profesor, en clase

7. Aprendí en casa con mis padres, hermanos

8. Leyendo las instrucciones que trae el diccionario

9. Aprendí yo solo con cl uso

\section{4.- USO DEL DICCIONARIO: DATOS INTERNOS}

4.1.- ¿Para qué usas nomalmente el diccionario? (señala hasta 6 casillas)

a) Para averiguar el significado de las palabras que no entiendo

b) Para comprobar cóno sc cscribe una palabra (ortografía)

d) Para saber si una palabra es sustantivo, verbo, adjetivo...

c) Para buscar un ejemplo (frase) de cómo se usa una palabra

1) Para saber si una palabra es de uso normal, vulgar, culta...

g) Para averiguar el género gramatical de una palabra (masc/fem)

b) Para saber cómo se forma el plural (club= ciubs, clubes)

i) Para saber si una palabra Ileva acento o tilde y en qué sílaba

j) Para saber la pronunciación de alguna palabra (bacon, beicon) 
k) Para buscar sinónimos (rojo, colorado), antónimos (caro,barato)

1) Para buscar el signilicado de una frase hecha (pedir peras al olmo)

m) Otros usos

\section{2.- ¿Quć defectos encuentras en tu diccionario? (señala hasta 5 casillas)}

n) Las explicaciones (definiciones) no son claras porque utiliza palabras dilíciles (anginas: inflamación de las amigdalas

ñ) Faltan ejemplos de cómo usar las palabras

o) Faltan ilustraciones, dibujos, gráficos, etc. pues las imágenes ayudan a comprender mejor el signilicado de las palabras

p) No trae señalización especial para el orden alfabético

(1) No siempre están en el diccionario las palabras que busco

1) No vienen las formas irregulares (anduve / andar, quepo / caber)

s) No entiendo bien las instrucciones de uso de mi diccionario

t) Es dilícil encontrar las frases hechas (Poner entre la espada y la pared ¿por qué palabra buscar esta expresion?)

u) No entiendo las abreviaturas, símbolos, grálicos del diccionario

w) Otras cosas que no estén en esta lista

4.3.- ¿Qué es lo que más te gusta de tu diccionario?

\section{1.- DATOS DEL I'ROFESOR}

\section{APÉNDICE 2}

SEXO:

Hombre

Mujer:

EDAD: $\quad$ Menos de 30

Entre $30-40$

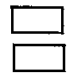

0

Entre 40-50 $\square$ Más de 50

ESTUDIOS: Licenciado $\square$ Maestro

UNIVERSIDAD DONDE ESTUDIÓ

¿HA REALIZADO ALGÚN CURSO DE LEXICOGRAFIA?

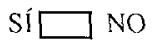

¿CUÁL ES SU LENGUA MATERNA

CASTELLANO:

VALENCIANO:

\section{2.-DATOS DEL CENTRO DE TRABAJO}

CENTRO DE TRABAJO:

Público

Privado

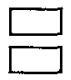


LOCALIDAD:

NIVEL DE ENSEÑANZA: Primaria: $\square$ ESO: $\square$ Bachillerato: $\square$

CURSO/S:

\section{3.- USO DEL DICCIONARIO: DATOS EXTERNOS}

- 3.i-¿Recomienda a sus allumnos el uso de algún diccionario ?

- 3.2- ¿En quién recac la elección del diccionario?

- En el profesor de Lengua

- En el colegio o centro docente

- Se deja al criterio de los alumnos, padres, etc.

3.3-_Dispone su centro de biblioteca? Sí

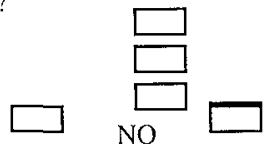

- ¿Recuerla el título de algún diccionario escolar que esté en dicha biblioleca?:

- ¿Recuerda la clitorial?:

3.4-¿Piensa que un mismo diccionario puede cubrir las necesidades de aprendizaje del alumno durante todas las etapals de su cscolarización? SÍ

$\mathrm{NO}$

\section{4.- USO DEL DICCIONARIO: FRECUENCIA Y APRENDIZAJE}

- 4.1-¿Usan sus alumnos el diccionario en clase? 'SI NO

- 4.2-En caso alfirmativo, señale en qué ocasiones lo usan:
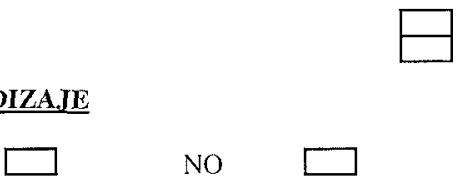

10. Lo tienen siempre a mano para cualquier duda que les surja

II. Sólo to usan cuando el profesor recomienda/obliga su empleo para realizar una tarea concreta.

12. Lo usan muy poco porque apenas hay tiempo para programar actividades con el diccionario

13. Otros

- 4.3-¿Quién debe enseñar a los alumnos a manejar el diccionario?

14. El prolesor, en clase

15. Los padres, hermanos, ete.

16. Nadic, puesto que el manejo del diccionario es tan sencillo que cualquier alumno que sepa leer con soltura puede utilizarlo.

17. Otros

\section{5.- USO DLL DICCIONARIO: DATOS INTERNOS}

5.1.- ¿Para qué usos recomienda a sus alumnos que consulten el diccionario? (señale hasta 6 casillas)

- a) Para averiguar el significado de las palabras

- b) Para comprobar cómo se escribe una palabra (ortografía)

- (l) Para comprobar la catcgoría gramatical (sustantivo, verbo, transitivo, etc...)

- c) Para buscar un cjemplo (frase o cita) de cómo se usa una palabra

- f) Para averiguar el nivel de uso de una palabra (formal, vulgar,dialectal, técnico,etc).. 
- g) Para averiguar el género gramatical de una palabra (masc/fem)

- h) Para saber cómo se forma el plural ( $c l u b=$ clubs, clubes)

- i) Para aclarar dudas sobre el régimen del verbo (colaborar conten/para)

- j) Para comprobar la pronunciación de algún extranjerismo(bacon, beicon)

- k) Para buscar sinónimos (rojo, colorado), antónimos (caro,barato)

- 1) Para buscar el signilicado de una frase hecha (pedir peras al olmo)

- m) Otros usos

5.2.- ¿Qué defectos más frecuentes señalaría en los diccionarios escolares que usan sus alumnos? (marque hasta 5 casillas)

- n) Las definiciones no son claras porque utilizan palabras que el alumno no conoce (anginas:

- inflamación de las amigdalas)

- ñ) Faitan cjemplos de cómo usar las palabras

- o) Faltan ilustraciones, dibujos, gráficos, etc. pues las imágenes ayudan a comprender mejor el significado de las palabras

- p) No traen scñalización especial para el orden alfabético

- 9) No sicmpre están en el diccionario todas las voces que el alumno necesita

- r) No aparecen como entradas las formas irregulares (anduve / andar, quepo / caber)

- s) Las instrucciones de uso no son lo suficientemente claras

- 1) Es dilícil encontrar las liases hechas (Poner entre la espada y la pared ¿por qué palabra

- buscar esta expresión?)

- u) No se cntienden las abreviaturas, símbolos, gráficos del diccionario

- w) Otros 